\title{
Program Improvement through Accreditation
}

\author{
Jeffrey Fergus
}

\section{INTRODUCTION}

Even before the Accreditation Board

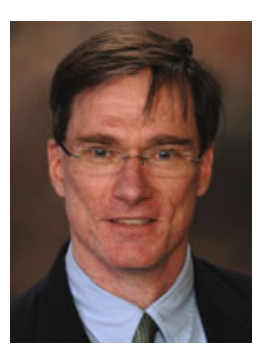

for Engineering and Technology in 2005 officially changed its name to ABET, Inc., it was a four-letter word that evoked negative, often passionately so, Jeffrey Fergus response among individuals from engineering programs. This is unfortunate because the accreditation process is an opportunity for improving the quality of academic programs. In fact, the vision and mission of ABET (www.abet.org/vision -mission) emphasize promoting innovation and quality improvement in engineering education. However, this noble purpose has sometimes been overwhelmed by the minutiae of details involved in meeting criteria that appear to be continuously changing. Although the criteria and the associated accreditation process are not perfect, they do provide a framework that can be used for real continuous quality improvement. The purpose of this article is to provide information that will help programs to better understand the accreditation process, so they can develop sustainable processes that have value for the program (and also happen to meet the accreditation criteria). See the sidebar on how to get involved with the TMS Accreditation Committee.

\section{ACCREDITATION PROCESS AND CRITERIA}

ABET accredits academic programs, not colleges or departments.
Institutions request evaluation of academic programs for accreditation and to maintain accreditation, programs must be reevaluated every six years. The climax of the evaluation is the campus visit, but the process of evaluation for accreditation or reaccreditation takes approximately one-and-ahalf years as is summarized in Figure 1. The process begins with a request for evaluation in January. Later in the spring, the visiting team is assembled and the date of the visit is set. During this time, programs are preparing selfstudy reports that are due in July and will be given to the program evaluators for review. Prior to the visit, the program evaluators contact the program with questions about the self-study report and then work with the program to set the schedule for the visit. Visits occur in the fall and usually start on a Sunday and end on a Tuesday. At the end of the visit, however, the process is only half over. After the visit, a statement describing the findings during the visit goes through editing to ensure that the recommendations are consistent with those of the hundreds of other evaluations that are occurring during the cycle. After this editing, a Draft Report is sent to the institution and the programs have the opportunity to report on how they have addressed any shortcomings identified during the visit. The response is evaluated and the report is modified to reflect changes made by the program to generate the Final Report. The Final Report is presented to the commission which then takes action. The only shortcomings that have any impact on the accreditation action are those that remain at the commission meeting in July-shortcomings that were present at the visit, but were resolved during due process do not affect accreditation.

There are currently two cycles under review. Programs on the 20112012 cycle (accreditation will start or be renewed in October 2012) have completed visits (fall 2011) and are in the due process period. Programs on the 2012-2013 cycle (accreditation will start or be renewed in October 2013) have requested evaluation and will soon begin setting the visit date and assembling the visiting team.

In a given accreditation cycle hundreds of different academic programs are evaluated by hundreds of different program evaluators. Maintaining consistency among such a large number of individuals (volunteers, no less) is

\section{ABOUT THE TMS ACCREDITATION COMMITTEE}

The TMS Accreditation Committee consists of individuals involved in the accreditation process as program evaluators, commissioners or board members for ABET. Program evaluators visit at most one program each year, while commissioners serve as chair for typically two visits per year. As a group, the TMS Accreditation Committee develops the program criteria for materials programs and provides input to the TMS representatives on the ABET Engineering Accreditation Commission and ABET Board of Directors. The committee meets at both Materials Science \& Technology conferences and the TMS Annual Meeting. These meetings are followed by a retraining session, which is open to anyone interested in learning more about the accreditation process. 
a significant challenge. One approach to achieving consistent evaluation is through training. The training of program evaluators has improved dramatically over the last several years. The training has multiple steps, but the most intensive portion is a one-anda-half day face-to-face training that simulates an accreditation visit. Some societies, including TMS, also require that program evaluators go on an observer visit, in which they shadow an experienced program evaluator on an actual ABET visit. Although improved training helps with consistency, addi- tional measures are needed. As noted above, the reports go through multiple editing stages to check for consistency. In addition, there is a committee assigned at the commission meeting specifically to identify consistency issues among final reports. Representatives from professional societies also caucus to ensure programs in their respective disciplines are evaluated consistently. All commissioners see all reports, which provides another check for consistency.

One of the complaints regarding ABET is that the criteria are a moving

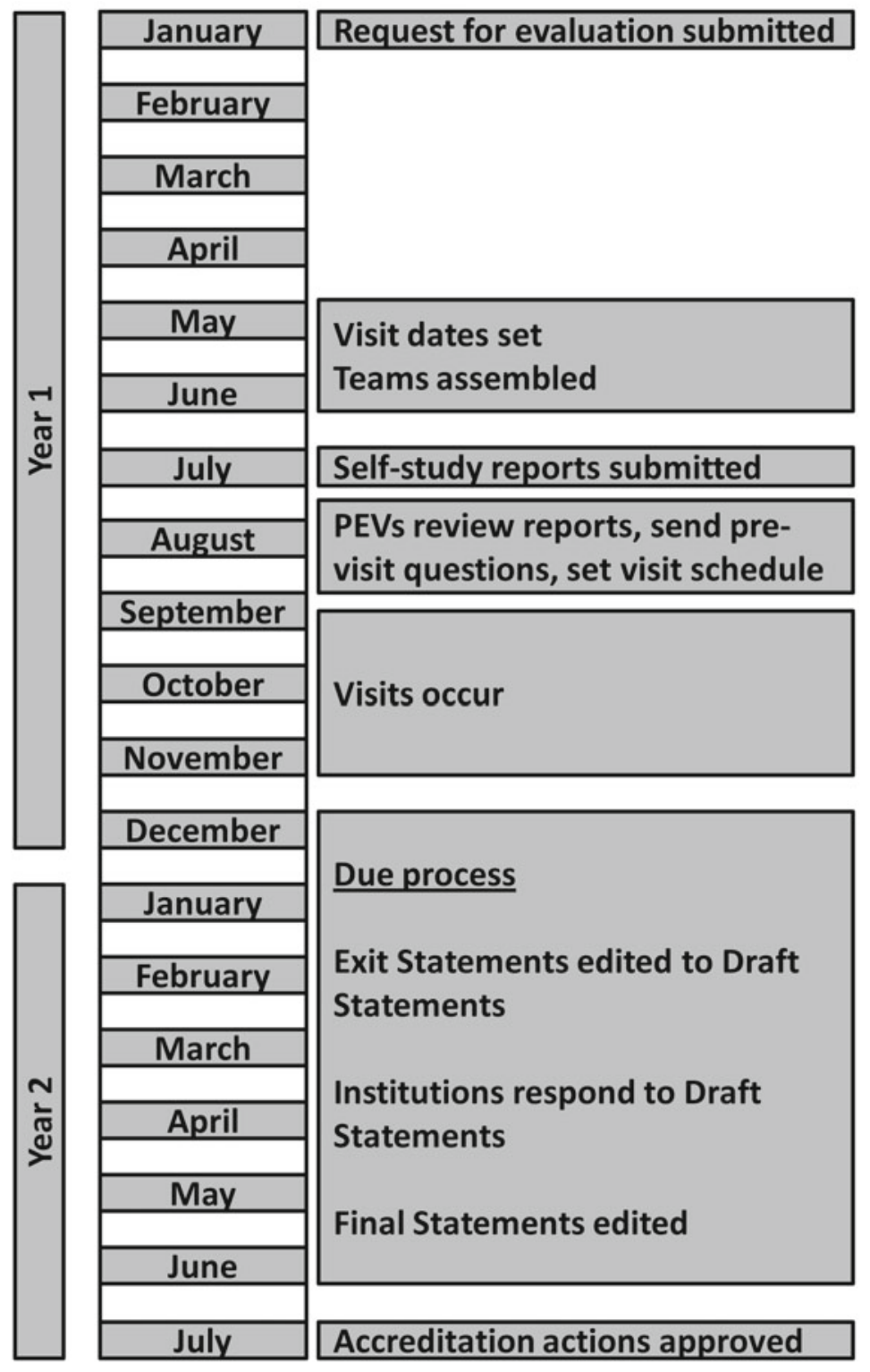

Figure 1. An accreditation timeline. target. Although these changes are in the spirit of continuous improvement, it can be difficult for individuals not involved in ABET to keep up with the changes. The change to EC2000 was significant and in the early years of EC2000 there were some ambiguities in the definition of terms, but for the last several years the fundamental requirements have not changed significantly. However, there have been changes in wording and even in the number of criteria, which has caused confusion. One of the reasons for these changes is the recent move to harmonize the criteria. Harmonization refers to making as much of the criteria the same as possible among the four commissions that constitute ABET. The four commissions are the Applied Science Accreditation Commission (ASAC), the Computing Accreditation Commission (CAC), the Technology Accreditation Commission (TAC), and the Engineering Accreditation Commission (EAC). Because of differences in the needs and nature of academic programs associated with these different commissions, all of the criteria could not be harmonized. Of the eight general criteria, five are common to all four commissions and three are different for the different commissions.

The criteria by which engineering programs are evaluated are summarized below. The complete criteria are available on the ABET website: www.abet.org/DisplayTemplates/Docs Handbook.aspx?id=747. The purpose of the following summary is to identify the basic requirements and reason that each criterion is important to preparing students for engineering careers.

C1. Students: Programs must provide the support needed for students to complete the degree requirements that are designed to prepare them for their future careers. This includes providing advice to students regarding course selection and career options as well as having processes in place to ensure that students meet all graduation requirements.

C2. Program Educational Objectives: As defined by ABET, pro- 
gram educational objectives describe what graduates are expected to attain within a few years of graduation. These objectives should be established and reviewed based on the needs of the constituencies of the program.

C3. Student Outcomes: Student outcomes describe the abilities and knowledge that students should demonstrate before graduating. ABET has established eleven outcomes, referred to as a-k, which must be included, but programs may include additional outcomes if appropriate to the objectives of the program.

C4. Continuous Improvement: All programs should strive to become better. The criterion requires that programs have systematic processes in place for continuous quality improvement. The processes must use results from assessment of student attainment of student outcomes and graduate attainment of program educational objectives as inputs, but can use any available information.

C5. Curriculum: The purpose of the curriculum is to prepare students to attain the student outcomes. The criterion does not have any specific course requirements, but does require that the curriculum includes at least one year of basic mathematics and science as well as one-and-a-half years of engineering topics. In addition, the curriculum must include a culminating design experience, which is based on earlier courses and involves appropriate standards and multiple realistic constraints.

C6. Faculty: Programs must have a sufficient number of appropriately qualified faculty members to prepare students to attain the program's student outcomes.

C7. Facilities: The facilities must be available to provide students with the experiences needed to prepare them for attaining student outcomes.

C8. Institutional Support: ABET accredits academic programs, but the effectiveness of the program depends on resources and admin- istrative support from the institution to implement and maintain the program.

In addition to the eight general criteria there are program criteria that identify additional requirements for the curriculum or faculty qualifications as appropriate for specific disciplines. In the case of materials science and engineering, the program criterion is organized around four elements: structure, properties, processing, and performance. The curriculum must address these elements and the faculty must have the qualifications needed to deliver instruction in these areas. The program criteria is the same for programs related to all different types of materials, e.g. metals, ceramics, polymers, or all materials. However, the content of the curriculum must be consistent with the name of the program.

The central purpose of these criteria is to prepare students for engineering careers as identified by the program educational objectives (C2), which requires skills and abilities described by the student outcomes (C3). Meeting those outcomes requires certain curricular content (C5) that must be presented by qualified faculty (C6) to properly-guided students $(\mathrm{C} 1)$ with access to the needed facilities (C7), all of which requires institutional support (C8). In addition to meeting these minimum standards, programs should strive to improve $(\mathrm{C} 4)$ and adapt to the increasing and changing challenges for which engineers are being prepared.

\section{MAKING ACCREDITATION WORK FOR THE PROGRAM}

The criteria with which programs typically have difficulties are Criteria 2, 3 and 4. The key to effectively addressing these criteria is to focus on what is useful and important to the program's students and graduates. These criteria are intended to address questions like the following:

- What do we hope and expect that our graduates will be achieving?

- What should students learn to do so that they can achieve what we hope for them to achieve?

- How do we make sure that students learn what we think we have taught them?

- How do we make our graduates more competitive in the engineering community?

Few would argue that the answers to these questions are not important for an engineering program. However, as is often the case, the devil is in the details as answering these questions can be difficult. Establishing, implementing, and documenting processes to determine if graduates are meeting expectations and if students are attaining student outcomes is a significant challenge. For a continuous improvement process to be effective, it must be sustainable. Collecting assessment data at a rate that cannot be maintained and in amounts that cannot be properly evaluated is counterproductive. Data should be collected continuously at rates that do not detract from educating students and in amounts that can be evaluated to provide useful information on the effectiveness of the program. If data is being collected that is not providing useful information, then the process should be modified to obtain useful data-improvement of the process is part of continuous quality improvement. The key to making the accreditation process work for the program is to focus on preparing students for engineering careers and design sustainable processes that provide useful information and then check to see if any modifications or additions are needed to satisfy the ABET criteria.

\section{CONCLUSION}

The general principles described by the engineering accreditation criteria are consistent with those of engineering programs. If faculty/administrators from academic programs and program evaluators representing ABET focus on these ideals with a positive attitude, the accreditation process can provide a framework for continuous quality improvement, such that the accreditation visit is viewed by programs as an opportunity to obtain input on ways to better prepare engineering students for engineering careers.

Jeffrey Fergus is a professor with the Materials Research and Education Center at Auburn University, Auburn, Alabama; and the chairperson of the TMS Accreditation Committee. 